\title{
The future of pediatric pulmonology: A survey of division directors, assessment of current research funding, and discussion of workforce trends
}

\author{
Terry L. Noah ${ }^{1}$ (ㅇ | Sue Tolleson-Rinehart ${ }^{1}$ | Charles R. Esther Jr. ${ }^{1}$ (ㅇ | \\ Stacey L. Peterson-Carmichael ${ }^{2}$ | Stephanie D. Davis ${ }^{1}$ | Paul E. Moore ${ }^{3}$ (1) \\ ${ }^{1}$ Department of Pediatrics, University of North Carolina at Chapel Hill, Chapel Hill, North Carolina, USA \\ ${ }^{2}$ Department of Pediatrics, Wake Forest University, Winston-Salem, North Carolina, USA \\ ${ }^{3}$ Department of Pediatrics, Vanderbilt University, Nashville, Tennessee, USA \\ Correspondence \\ Terry L. Noah, Department of Pediatrics, University of North Carolina at Chapel Hill, 450 Macnider Bldg, Campus Box 7217 , \\ 333S. Columbia St, Chapel Hill, NC 27599, USA. \\ Email: terry_noah@med.unc.edu
}

\section{1 | INTRODUCTION AND BACKGROUND}

Adequacy of the US workforce in pediatric pulmonology has been a source of serious concern within the field for some time, as it has been for several pediatric subspecialties. ${ }^{1-7}$ Contributing factors have been thought to include low fill rates of fellowship training programs, aging, and retirement rates of the subspecialist population, and the perception of insufficient numbers of specialists in some regions to meet clinical care needs. Several approaches to assessing workforce needs have already been described, ${ }^{1,2,5}$ and stakeholder groups are currently working on additional analyses. Although the recent report by Harris et al. ${ }^{1}$ captured a broad snapshot of workforce perceptions of 485 pediatric pulmonologists, this study (reporting data collected in 2014) did not address the future scope of practice.

In 2018-2020, The American Thoracic Society's Pediatric Pulmonology Division Directors Association (PPDDA) and Pediatric Pulmonology Training Directors Association (PEPTDA) convened a series of workshops to analyze workforce issues from the perspectives of current leaders within the discipline. In this, the report from the third workgroup, we examine future workforce issues from several perspectives, including anticipated changes in the nature of our clinical and research priorities. The report is organized into sections describing (1) a recent new PPDDA survey regarding the current state and future needs of the discipline; (2) an assessment of the current $\mathrm{NIH}$ research funding portfolio for major children's respiratory disorders; (3) an estimate of workforce trends in training, based mainly on ABP data; (4) perspectives on other issues pertinent to the future of the discipline; and (5) summary and overall conclusions.

\section{2 | CURRENT STATE AND FUTURE PRIORITIES FOR PEDIATRIC PULMONOLOGY: PPDDA MEMBERSHIP SURVEY}

In late 2019, we administered a survey to the PPDDA membership, asking for detailed responses regarding their group's characteristics, and their opinions regarding the future clinical and research priorities of the discipline. PPDDA's membership roster includes current and a few former division directors built largely from attendees at the annual American Thoracic Society and North American Cystic Fibrosis conferences over the past several years. While PPDDA's membership is more representative of academic versus nonacademic medical centers, a wide range of program size and mission focus is represented, as well as a range of views regarding our discipline's future, as is borne out by the data we present here. The survey was approved by the UNC Biomedical Institutional Review Board.

Our survey was sent to 99 individuals from 72 institutions, and there were 38 responses. To encourage openness in responses, we did not ask respondents to self-identify; thus we cannot identify the specific institutions that are included or rule out the possibility that some institutions are represented by more than one response. The following sections describe the survey results, yielding a snapshot of the current structure and status of the respondents' groups as well as their clinical scope of practice and perceived clinical and research priorities over the next 5-10 years.

To understand the context of the responses, we asked a series of questions about each respondent's clinical and training programs, 
and faculty. All responses were from academic medical centers, defined as being part of a Department of Pediatrics in a medical school. Sixty-five percent reported that they work in a "free-standing" children's hospital, and for $73 \%$ the children's hospital is part of a larger healthcare system. Sixty-two percent of respondents reported that their health system is publicly funded. Patients were reported to be insured by Medicaid for an average (SD) of $48 \%$ (23), private/ commercial insurance for $33 \%$ (19), with small percentages insured by vertically integrated health plans (e.g., Kaiser), self-pay, or uncompensated care. Program size as evidenced by numbers of physicians varied substantially among the respondents, with $19 \%$ having $\leq 4$ MD providers, $38 \%$ having $5-8,25 \%$ with $10-14$, and $19 \%$ having $\geq 15$ providers. Most (88\%) of MD providers were reported to be American Board of Pediatrics (ABP) eligible or certified in pediatric pulmonology. A sleep board-certified physician was a member of $75 \%$ of programs. Sleep physician consultations were provided by a pediatric pulmonologist in $58 \%$ of programs, a pediatric neurologist in $34 \%$, an adult neurologist in $16 \%$, and an adult pulmonologist in $11 \%$ (more than one could be selected). To address whether our sample was representative of the target "population" (the PPDDA roster's institutions), we reviewed the websites of each of the PPDDA-represented programs. Our sample was broadly representative of the roster in terms of the academic setting and provider number, but had a higher percentage of active fellowships (Table 1).

While a large majority of respondents indicated that they continue to have a specific Pediatric Pulmonology inpatient service, it is of note that $16 \%$ did not. Current estimated average daily census for programs with a dedicated pediatric pulmonology inpatient service was $\leq 6$ patients for $26 \%, 7-12$ patients for $52 \%$, and $\geq 15$ for $22 \%$ of programs. Of those with an inpatient service, $67 \%$ reported that their census had fallen in the past 3 years; $26 \%$ indicated no change, and $7 \%$ reported an increase. Estimated numbers of inpatient consultations per week were reported to be $\leq 6$ for $19 \%, 7-12$ for $56 \%$, and $\geq 14$ for $26 \%$ of respondents. Numbers of bronchoscopies per week were estimated at $\leq 5$ for $56 \%$, $6-10$ for $26 \%$, and $\geq 12$ for $19 \%$. Individual comments regarding recent inpatient service trends emphasized decreases in

TABLE 1 Comparison of program characteristics between the survey sample and institutions in the PPDDA roster (population to which the survey was administered)

$\begin{array}{lll}\text { Characteristic } & \text { Survey result } & \text { PPDDA roster } \\ N & 38 & 72 \\ \text { Academic setting (medical } & 100 & 90 \\ \quad \text { school, \%) } & & \\ \quad \text { 4 providers } & 19 & 21 \\ \text { 5-8 providers } & 38 & 29 \\ \text { 9-14 providers } & 25 & 29 \\ \geq 15 \text { providers } & 19 & 21 \\ \text { Active fellowship } & 86 & 62\end{array}$

Abbreviation: PPDDA, American Thoracic Society's Pediatric Pulmonology Division Directors Association.

${ }^{a}$ Estimated from publically available information on the program website. cystic fibrosis (CF) admissions and competition with hospitalist services for some patients (Table 2).

These comments are generally consistent with recent literature on pediatric hospitalization trends in the United States. In pediatric asthma, the rates of asthma diagnoses and hospitalizations have been slowly dropping since the turn of the century. ${ }^{8,9}$ The situation is more complex in CF, because a recent analysis suggested that pediatric CF-related hospitalizations were actually increasing through $2013 .{ }^{10}$ However, that report largely preceded the approval of cystic fibrosis transmembrane conductance regulator (CFTR) modulator therapy, which has been associated with significant reductions in $\mathrm{CF}$ exacerbation-related hospitalizations in clinic trials. ${ }^{11}$ The recent approval of highly effective triple modulator therapy is predicted to further decrease the need for inpatient CF care dramatically. ${ }^{12}$ For children with tracheostomy, a recent study suggested that while overall rates of tracheostomy may not be increasing, care has become increasingly complex, ${ }^{13}$ which could result in greater inpatient care needs.

Regarding definitions of full-time clinical work (1.0 full-time equivalent $[F T E])$, the reported average $(S D)$ number of clinic half-days per week was 6.3 (1.4), though the range of responses (minimum $=4$, maximum $=8.5$ ) was quite wide. For most respondents (87\%), outpatient clinics included both general pulmonology clinic and specific condition-oriented clinics (e.g., CF, chronic ventilation, etc.). Of the 27 respondents who described their clinics in detail, the most commonly reported multidisciplinary clinics were for CF, sleep disorders, chronic ventilator patients, and neuromuscular disease (NMD; Table 3).

Fellows played a significant role in the delivery of pediatric pulmonary care, with most (86\%) programs in the survey associated with a fellowship training program. The majority of respondents reported offering either 1 (48\%) or 2 (30\%) fellowship positions per year. Roughly a quarter of programs currently had not filled at least one of the three training years of their program (Table 4). It is important to note that the data in Table 4 are not overall fellowship fill rates, but were included to show the overall distribution of the size of fellowship programs by year of training within the respondents' institutions. As discussed in more detail in an accompanying article in this series, on fellowship training, fellowship fill rates (including slots filled outside of the match) are actually closer to $90 \%$ over the past decade. This is broadly consistent with an overall fill rate of $75 \%$ of programs over 3 years of training as reported in the survey. Funding resources for fellowships included NIH T32 grants for $42 \%$ of programs; Cystic Fibrosis Foundation grants for 71\%; clinical funds for $67 \%$; and other mechanisms including hospital or department funds for $75 \%$.

PPDDA survey respondents were asked to rank their anticipated proportion of clinical effort for the scope of practice over the next 5-10 years, and to provide comments on this. Table 5 shows that asthma was the clear top response. Interestingly, CF is anticipated to continue to require a high proportion of clinical effort despite a number of indicators that it is declining as an inpatient focus. While environmental respiratory disease was not included as a specific item 
TABLE 2 Summary of free text comments, from PPDDA survey

\begin{tabular}{|c|c|c|}
\hline Domain & $\begin{array}{l}\text { Number of } \\
\text { comments }\end{array}$ & Representative comment(s) \\
\hline $\begin{array}{l}\text { Changes in } \mathrm{CF} \text { care, especially the } \\
\text { reduction of inpatient care }\end{array}$ & 13 & $\begin{array}{l}\text { "With the introduction of CFTR modulators, there has been a noticeable shift in our } \\
\text { inpatient population. We went through two weeks with no CF admissions. This } \\
\text { has never happened before. This will impact inpatient and ambulatory activity." }\end{array}$ \\
\hline $\begin{array}{l}\text { Inpatient:outpatient shifts, competition } \\
\text { with hospitalists }\end{array}$ & 6 & $\begin{array}{l}\text { "With the growth of the hospitalist program, my sense is that our inpatient service } \\
\text { will become more focused on pulmonary complications in the NICU, PCCU, } \\
\text { and PICU." }\end{array}$ \\
\hline More multidisciplinary clinics & 6 & $\begin{array}{l}\text { "The development of specialized clinics/programs within our Division will enable us } \\
\text { to improve care (and set standards for care) in the inpatient and ambulatory } \\
\text { settings." }\end{array}$ \\
\hline $\begin{array}{l}\text { Increased involvement with } \\
\text { technology-dependent patients }\end{array}$ & 6 & "More need for trach/vent expertise and NMD expertise" \\
\hline $\begin{array}{l}\text { Changes in involvement in asthma care } \\
\text { (comments in both directions) }\end{array}$ & 6 & $\begin{array}{l}\text { "Asthma still a big proportion of our work" } \\
\text { "Asthma will decrease as pediatricians, hospitalists and allergist, take a larger } \\
\text { proportions of patients" }\end{array}$ \\
\hline Increased involvement in sleep medicine & 2 & $\begin{array}{l}\text { "Sleep disorders will continue to grow, given the obesity epidemic and the rising } \\
\text { frequency of autism" }\end{array}$ \\
\hline Increased involvement in BPD & 2 & "We also have an opportunity to grow with neonatology in BPD/CLD" \\
\hline Other & & $\begin{array}{l}\text { "A particularly fertile area for expansion is the growing field of Children's } \\
\text { Environmental Health (also known as Environmental Pediatrics)." }\end{array}$ \\
\hline
\end{tabular}

Abbreviations: BPD, bronchopulmonary dysplasia; CF, cystic fibrosis; CFTR, cystic fibrosis transmembrane conductance regulator; CLD, chronic lung disease; NICU, neurological intensive care unit; NMD, neuromuscular disease; PCCU, pediatric cardiac care unit; PICU, pediatric intensive care unit; PPDDA, American Thoracic Society's Pediatric Pulmonology Division Directors Association.

to be ranked, there were individual comments on this, as for sickle cell disease-related respiratory issues.

In a similar fashion, survey questions addressed anticipated research priorities over the next 5-10 years. Not surprisingly, rank

TABLE 3 Percent of programs with specific clinics for chronic respiratory disorders, from the PPDDA survey

$\begin{array}{llll} & \begin{array}{l}\text { \% or programs } \\ \text { with specific } \\ \text { clinic }\end{array} & \text { Condition } & \begin{array}{l}\text { \% or programs } \\ \text { with specific } \\ \text { clinic }\end{array} \\ \text { CF } & 68 & \text { PCD } & 26 \\ \text { Trach/vent } & 55 & \text { ChILD } & 18 \\ \text { Neuromuscular } & 55 & \text { Exercise } & 14 \\ \text { Sleep disorders } & 55 & \text { Pulmonary HTN } & 14 \\ \text { BPD } & 45 & \text { Sickle cell disease } & 9 \\ \text { Aerodigestive } & 45 & \text { Transplant } & 5 \\ \text { Asthma } & 41 & \text { Spine } & 5 \\ & & \text { CDH } & 5\end{array}$

Abbreviations: BPD, bronchopulmonary dysplasia; $\mathrm{CDH}$, congenital diaphragmatic hernia; CF, cystic fibrosis; ChILD, childhood interstitial lung disease; HTN, hypertension; PCD, primary ciliary dyskinesia; PPDDA, American Thoracic Society's Pediatric Pulmonology Division Directors Association. order of responses at the top (asthma, CF) was quite similar to that for clinical scope of practice (Table 6), but there was a greater variety of responses regarding other disorders, as suggested by the clustering of median and modal ranks.

Finally, respondents were asked to provide free-text comments regarding the future of the specialty. The responses were wide ranging, thoughtful, and sometimes contradictory. Many respondents commented on the changing nature of CF care, and our opportunities for a shift toward other facets of respiratory care enabled by new technologies, the application of our specialty's skills in chronic disease management, and the move toward personalized medicine including biologics. The frequency of comments about the future scope

TAB LE 4 Percent of fellowship positions currently filled, by year of training, for PPDDA survey respondents

$\begin{array}{llll}\text { Positions filled } & \text { Year 1 (\%) } & \text { Year 2 (\%) } & \text { Year 3 (\%) } \\ 0 & 23 & 26 & 22 \\ 1 & 50 & 30 & 44 \\ 2 & 18 & 35 & 26 \\ 3 & - & - & 4 \\ \text { Other response } & 9 & 9 & 4\end{array}$

Abbreviation: PPDDA, American Thoracic Society's Pediatric Pulmonology Division Directors Association. 
TAB LE 5 Rank order of clinical priorities for next 5-10 years, from PPDDA survey

$\begin{array}{lllll} & \text { Disorder } & \text { Mean (SD) } & \text { Median } & \text { Mode } \\ 1 & \text { Asthma } & 2.0(1.5) & 1 & 1 \\ 2 & \text { CF } & 4.0(2.8) & 3 & 1 \\ 3 & \text { Bronchopulmonary dysplasia } & 4.5(2.4) & 4 & 2 \\ 4 & \text { Sleep disorders } & 4.6(2.2) & 5 & 3 \\ 5 & \text { Technology/vent dependent } & 5.4(3.0) & 5 & 8 \\ & \quad \text { disorders } & & & \\ 6 & \text { Neuromuscular disease } & 5.5(2.0) & 6 & 7 \\ 7 & \text { Aerodigestive disorders } & 6.1(2.6) & 6 & 6 \\ 8 & \text { Aspiration syndromes } & 6.7(2.6) & 6 & 9 \\ 9 & \text { ChILD } & 8.7(1.5) & 8 & 8 \\ 10 & \text { Non-CF bronchiectasis } & 9.4(2.0) & 10 & 11 \\ 11 & \text { Pulmonary hypertension } & 9.7(1.9) & 10 & 10 \\ 12 & \text { Other (included SCD, } & 11.4(1.8) & 12 & 12\end{array}$

Abbreviations: CF, cystic fibrosis; ChILD, childhood interstitial lung disease; PPDDA, American Thoracic Society's Pediatric Pulmonology Division Directors Association; SCD, sickle cell disease.

of practice in several domains is shown, with representative comments quoted, in Table 2.

Our aim was to solicit perspectives on the future of the discipline from a programmatic perspective, focusing on the clinical and research missions. We surveyed division directors because they are

TABLE 6 Rank order of research priorities for next 5-10 years, from PPDDA survey

\begin{tabular}{llrll} 
& Disorder & Mean (SD) & Median & Mode \\
1 & Asthma & $2.2(1.5)$ & 2 & 1 \\
2 & CF & $2.5(2.6)$ & 1 & 1 \\
3 & Bronchopulmonary dysplasia & $5.2(2.4)$ & 5 & 7 \\
4 & Neuromuscular disease & $5.3(1.4)$ & 5 & 6 \\
5 & Sleep disorders & $5.8(2.8)$ & 6 & 3 \\
6 & ChILD & $6.0(2.8)$ & 6 & 6 \\
7 & Technology/vent dependent & $7.1(3.1)$ & 6 & 6 \\
8 & disorders & & & \\
9 & Nerodigestive disorders & $8.0(2.3)$ & 8 & 10 \\
10 & Pulmonary hypertension & $8.5(3.1)$ & 10 & 11 \\
11 & Aspiration syndromes & $8.6(3.2)$ & 10 & 11 \\
12 & Other (included SCD, & $8.7(1.2)$ & 10 & 11 \\
\cline { 2 - 4 } & environmental disease) & $10.2(3.8)$ & 12 & 12
\end{tabular}

Abbreviations: CF, cystic fibrosis; ChILD, childhood interstitial lung disease; PPDDA, American Thoracic Society's Pediatric Pulmonology Division Directors Association; SCD, sickle cell disease. likely to have direct engagement in and responsibility for programmatic and planning issues, as well as training and development of the workforce. The larger survey reported recently by Harris et al. ${ }^{1}$ focused on describing the status of individual pediatric pulmonologists, and did not address the future scope of practice. A clear limitation of our approach targeting academic division directors is that it may not represent the perspectives of physicians managing childhood respiratory diseases in other settings. However, the majority of respondents in Harris et al. ${ }^{1}$ were engaged in teaching and/or research, suggesting that at least a large proportion of our discipline is working in academic settings.

\section{3 | ANALYSIS OF NIH FUNDING PORTFOLIO FOR CHILDREN'S RESPIRATORY DISORDERS}

As a companion to the PPDDA survey regarding research priorities, we assessed the current NIH funding portfolio for the pediatric respiratory conditions rated in the survey. We carried out a systematic search of the NIH RePORTER public database (see Supporting Information for search parameters and strategy). ${ }^{14}$ Search terms consisted of the disorder name and "pediatric," and abstracts were reviewed to filter out projects not directly relevant to pediatric respiratory disorders.

The results of this search are shown in Table 7. A total of 371 grants meeting these search criteria were actively funded as of February 2020, totaling $\$ 218$ million in direct costs. The great majority of funding ( $\$ 165$ million) was for grants related to asthma, followed by CF ( $\$ 18$ million).

The number of current grants with a pediatric pulmonologist as principal investigator (PI) was estimated by comparing $\mathrm{PI}$ names for these same grants with the ABP's public roster of board-certified specialists. In total, 51 of the 371 grants (about 14\%) fell into this category. Of these 51 Peds Pulmonology-led grants, there was one each for F32, M01, and P01 grants, 17 were K-series grants (10, K08 and 5, K23), 3 were T32, 20 were R series (10, R01), and 5 were U-series grants.

Caveats are that some of these projects may have little to do with children, and it is possible that some grants related to pediatric disease were not picked up by our search strategy. Some grant topics were relevant to but not specific to respiratory disorders. For example, studies of environmental or nutritional factors affecting children's health were excluded from this analysis. It is also likely that substantial NIH funding exists for pediatric pulmonologists as coinvestigators rather than PIs, information about which is not included in NIH RePORTER data.

If healthcare expenditures can be seen as a proxy for disease burden, there are data sources that allow a rough comparison of research funding to disease burden. About a quarter of the US population is under age 19 years, and around 10\% of total health expenditures are directed to children, much of which goes to a smaller number of children with medical complexity. ${ }^{15}$ A comprehensive analysis of expenditures in 2013 for children in the United States ${ }^{16}$ 
TABLE 7 Current NIH funding for projects related to specific pediatric respiratory disorders from NIH RePORTER data downloaded in March 2020

\begin{tabular}{|c|c|c|c|c|c|}
\hline & Pediatric disorder & Direct costs & $\begin{array}{l}\% \text { NIH } \\
\text { budget }^{\mathrm{a}} \text { for } \\
\text { condition }\end{array}$ & $\begin{array}{l}\text { Number of } \\
\text { grants }\end{array}$ & $\begin{array}{l}\text { Pediatric } \\
\text { pulmonologist } \\
\text { as PI }\end{array}$ \\
\hline 1 & Asthma & $\$ 165,380,000$ & $79 \%$ & 223 & 20 \\
\hline 2 & Cystic fibrosis & $\$ 18,460,000$ & $33 \%$ & 45 & 14 \\
\hline 3 & Respiratory microbiome & $\$ 11,670,000$ & $2 \%$ & 18 & 1 \\
\hline 4 & $\begin{array}{l}\text { Bronchopulmonary } \\
\text { dysplasia }\end{array}$ & $\$ 10,800,000$ & $4 \%^{\mathrm{b}}$ & 42 & 3 \\
\hline 5 & Pulmonary hypertension & $\$ 6,790,000$ & $\mathrm{~N} / \mathrm{A}$ & 22 & 7 \\
\hline 6 & $\begin{array}{l}\text { Respiratory complications } \\
\text { of sickle cell disease }\end{array}$ & $\$ 1,260,000$ & $1 \%$ & 2 & 1 \\
\hline 7 & Interstitial lung disease & $\$ 1,040,000$ & $<1 \%^{\mathrm{c}}$ & 4 & 2 \\
\hline 8 & Aerodigestive disorders & $\$ 579,000$ & $\mathrm{~N} / \mathrm{A}$ & 3 & 0 \\
\hline 9 & Aspiration syndromes & $\$ 318,000$ & $\mathrm{~N} / \mathrm{A}$ & 4 & 1 \\
\hline 10 & $\begin{array}{l}\text { Technology/ventilator- } \\
\text { dependent disorders }\end{array}$ & $\$ 310,000$ & $\mathrm{~N} / \mathrm{A}$ & 1 & 0 \\
\hline 11 & Sleep disorders & $\$ 264,000$ & $<1 \%$ & 2 & 1 \\
\hline 12 & Non-CF bronchiectasis & $\$ 161,000$ & $\mathrm{~N} / \mathrm{A}$ & 1 & 1 \\
\hline 13 & Neuromuscular disorders & $\$ 146,000$ & $<1 \%^{\mathrm{d}}$ & 1 & 0 \\
\hline & Total & $\$ 217,740,000$ & $7 \%{ }^{e}$ & 371 & 51 \\
\hline
\end{tabular}

Abbreviations: CF, cystic fibrosis; PI, principal investigator; SMA, spinal muscular atrophy. ${ }^{a}$ Calculated as costs/NIH 2019 budget for condition, adjusted for estimated direct costs.

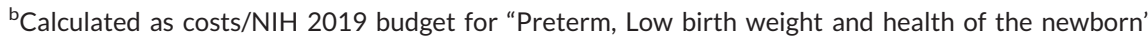
adjusted for estimated direct costs.

'Calculated as costs/NIH 2019 budget for "rare diseases" adjusted for estimated direct costs. dCalculated as costs/NIH 2019 budget for "SMA" + "muscular dystrophy" adjusted for estimated direct costs.

eCalculated as total costs/NIH 2019 budget for "pediatric disorders" adjusted for estimated direct costs. suggested that $8 \%$ of all spending for children was for "long-term respiratory disease," half of which was for asthma care. Based on these figures, chronic respiratory disease in children might be estimated as $0.10 \times 0.08=0.8 \%$ of the total healthcare burden .

Taking our total of $\$ 218$ million in direct costs for pediatric respiratory grants in 2019 (Table 7), adjusting for estimated indirects, and then comparing to the NIH overall budget for 2019 ( $\$ 39$ billion), ${ }^{17}$ it would appear that about $0.8 \%$ of overall $\mathrm{NIH}$ spending goes to pediatric pulmonary disorders, a figure closely matching the disease burden calculation above and suggesting that allocation of funds for pediatric respiratory disorders, as a whole, proportionally reflects disease burden.

Table 7 also estimates the percent of NIH budget for each condition spent on pediatric-specific or -inclusive studies, based on data from NIH on categorical spending in 2019. This suggests that substantial fractions of all grants for asthma and CF are directed to pediatric studies, while this fraction is much lower for the other disorders we manage, where data are available. It is difficult to form conclusions about the "sufficiency" of this without more granular information as to the adult diseases and definitions included in the $\mathrm{NIH}$ disease categories; and in any case, proportional allocation does not in itself ensure sufficient funds to meet research goals. However, it can be concluded that the vast majority of NIH funding for research in pediatric lung disorders appears to be for asthma, CF, BPD, and respiratory microbiome studies, with relatively little for other disorders that are currently considered part of the clinical scope of the discipline. In addition, the discipline's current funding portfolio appears to have a fairly large proportion of training or early-career grants, relative to more independent or later career awards.

Federal support for childhood asthma research is robust, and most of the grants directed at this condition are to Pls outside our discipline. The same is true on a lower scale for CF, though many pediatric pulmonology investigators are funded by nonfederal grants such as the Cystic Fibrosis Foundation. This analysis is clearly not a comprehensive assessment of our field's research portfolio, as many pediatric pulmonologists conduct research funded by industry, foundations, or other non-NIH sponsors. But it would appear that there is an opportunity for improvement of our presence in $\mathrm{NIH}$-supported research, particularly in asthma, which is the condition dominating healthcare expenditures in our field, and which was highlighted in the PPDDA survey as a future clinical and research priority (Tables 5 and 6). 


\section{4 | WORKFORCE: CURRENT DATA AND ESTIMATION OF FUTURE TRENDS}

Data from the ABP suggest that the number of new boardcertified pediatric pulmonologists added to the workforce has been steady over the past decade at a rate of $\sim 50$ new diplomates per year, ${ }^{18}$ suggesting that growth is likely to continue at this pace. However, this alone does not indicate whether this rate of growth is sufficient to maintain the workforce. Per the ABP, the total number of pediatric pulmonologists ever board-certified has grown steadily over time, reaching a total of 1418 in $2018 .{ }^{19}$ This number does not account for those who have retired or otherwise left active practice. The ABP uses age as a surrogate marker for retirement, estimating that there were 1260 active providers in 2018 under the age of 70. However, this does not account for providers who leave active practice at younger ages, or those who continue to practice after age 70 .

An alternative approach is to evaluate the relationship between age and inactive status on ABP board certification, which generates a "retirement curve" that follows an exponential relationship (Figure 1A). A rough model of the active workforce over time can be developed using the number of new boardcertified pediatric pulmonologists (actual data through 2018, 50/year thereafter), the fraction that leaves the workforce (the "retirement curve"), and reasonable estimates of age at first certification (34 years). In this model, the number of active
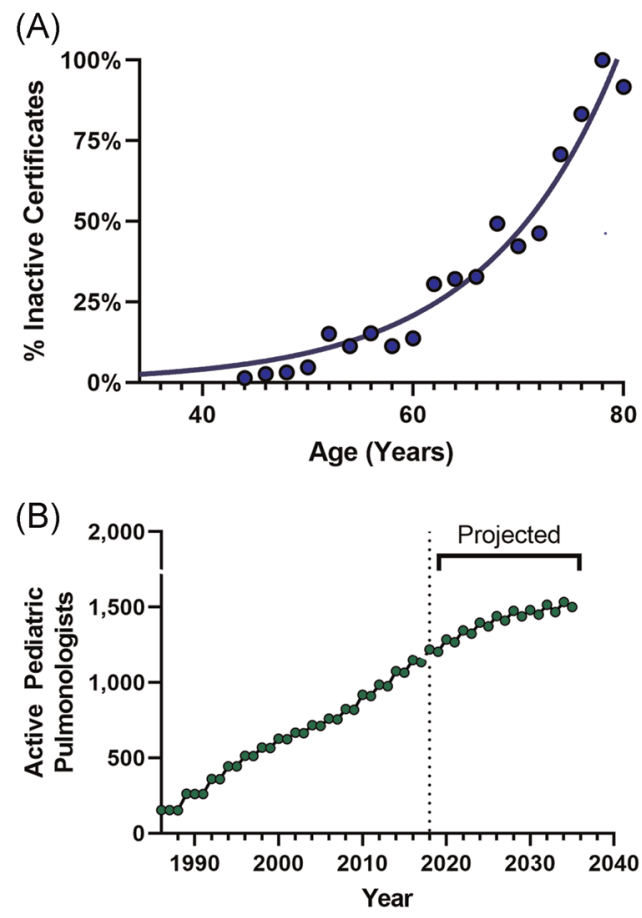

FIGURE 1 (A) Percent inactive (retired) American Board of Pediatrics certificates in pediatric pulmonology, by age, and (B) past and projected future numbers of active certificates holders based on age of retirement and other data trends ${ }^{18}$ as described in the text [Color figure can be viewed at wileyonlinelibrary.com] pediatric pulmonologists in 2018 was 1219 providers, a number comparable to ABP estimate using age 70 as a proxy. Extrapolating forward, the active workforce is predicted to grow at a modest rate over the next two decades (Figure 1B). While this model suggests that the total number of pediatric pulmonologists is unlikely to contract in the near future, it does not take into account those that have or plan to cut back on clinical workload. Although only $8.1 \%$ of pediatric pulmonologists in a recent survey were not planning to maintain certification over the next 5 years (similar to a $7.4 \%$ estimate from the calculations above), one-third of the respondents indicated plans to cut back on clinical workload. ${ }^{1}$ Modeling such cut backs is difficult as the survey did not address the extent of cut backs or if these rates have been changing with time. Adjusting the model to assume that providers cut back on clinical workload using reasonable but arbitrary values (e.g., $25 \%$ cutback after 20 years full time) changes the number of available providers but not the overall trends. Even in highly unrealistic scenarios (no cutbacks before 2018, 50\% cutbacks after 20 years full time starting in 2019), the model suggests that workforce numbers drop initially then recover within 10 years (not shown).

Of note, this kind of modeling does not take into account actual workforce need, which is complex and depends on population projections and potential changes in the scope of both clinical practice and research needs. Furthermore, the available data from ABP upon which this model is based only address the overall size of the workforce, not the fraction who are physician-scientists or clinicians. One way of addressing need or demand indirectly is by looking at subspecialty wait times, which were assessed in a 2017 Children's Hospital Association (CHA) survey. ${ }^{20}$ In that survey, $48 \%$ of patients had a wait time of $>2$ weeks for appointments in pediatric pulmonology suggesting that demand is outpacing supply at present. This figure was similar to wait times for pediatric rheumatology, and shorter than for pediatric endocrinology or pediatric neurology, but longer than for pediatric cardiology or pediatric infectious disease. Wait times, however, can be influenced by many variables and are an imperfect proxy for demand.

We are aware that other efforts are underway to provide more detailed workforce modeling for pediatric pulmonology and other subspecialties. For example, the ABP and UNC's Cecil G. Sheps Center for Health Services Research are currently developing a model to forecast the workforce (total number and clinical effort) for 14 pediatric subspecialties at national and regional levels from 2018 to 2040 . Our hope is that the information and discussion provided here is helpful for those assessments.

\section{5 | SUMMARY, CONCLUSIONS, AND FUTURE DIRECTIONS}

The data described above paint a complex and shifting picture of the future of the pediatric pulmonology workforce and its clinical and research priorities. Nevertheless, a few trends appear to be emerging and are briefly summarized here. 


\section{1 | Projected workforce based on recent trends and current numbers}

Current fellowship graduation rates, which have been stable for the last decade, appear to be sufficient to maintain and even grow the total number of pulmonologists. This is in contrast with common perceptions in our discipline. However, what is harder to assess is how these workforce numbers compare to need and demand. Wait time surveys suggest that demand for pediatric pulmonologists remains greater than supply, and there continue to be significant geographical disparities in access to care, similar to other pediatric subspecialties.

\section{2 | Clinical scope of practice}

The practice of pediatric pulmonology will probably look different for the next generation of pediatric pulmonologists. CF will continue to occupy an important place in our clinical practice, though highly effective CFTR modulators will almost certainly reduce the number of people with CF on our inpatient services. Asthma is a high priority from the clinical (as well as research) standpoint, and our specialty is well positioned to maintain a central role in the care of the severe or difficult to treat the asthmatic child. Several survey respondents pointed out the opportunities we have for a stronger niche in the care of the technology-dependent child, such as children with NMD whose prognoses may change with newer therapies. In addition, the pediatric pulmonologist may have a more vital position as a consultant in the NICU, where advances in the care of extremely low gestational age newborns have resulted in increased rates of moderate and severe BPD, including infants who are technology dependent. The COVID-19 epidemic highlights that respiratory infection treatment and infection control may become larger issues for our specialty. The trend toward multidisciplinary care teams, which has been exemplified by the impact of CF care on outcomes over the past several decades, is being applied to a number of other disorders, including children with NMD, aerodigestive diagnoses, interstitial lung disease, sickle cell disease, primary ciliary dyskinesia, and pulmonary hypertension. These approaches may even be cost-effective to the extent that they prevent unnecessary hospital admissions or reduce admission time..$^{21-23}$

\subsection{New ways to integrate with other specialties and types of providers for clinical care}

The growth of pediatric hospital medicine is changing our inpatient services. A challenge will be how to utilize the efficiencies of hospital medicine, but maintain the continuity of care optimal for the management of children with chronic respiratory conditions. In contrast, there may be an opportunity for the growth of our roles in inpatient as well as outpatient care for technology-dependent children. Properly designed models of integrated regional care using advanced practice or primary care providers may allow greater extension of a limited pediatric pulmonology workforce.

\subsection{Research trends and opportunities}

Currently, there is a large NIH portfolio of funding for asthma research, and relatively large resources being directed to CF, BPD, microbiome, and pulmonary hypertension, compared with other chronic respiratory disorders of children. Relatively few of these grants are led by pediatric pulmonologists, and as noted by other commentators, ${ }^{24}$ our training of physician-scientists needs to improve. To take advantage of this and to advance our understanding and management of these conditions, it will be important for our field to take a hard look at how we train the next generation of physician-scientists and clinical researchers. In addition, as it seems likely that we will play increasingly central roles in the care of technology-dependent children, it will be important to develop mechanisms for funding training and research in this area, likely in collaboration with not only federal but also industry sponsors.

There are several other factors that may impact the discipline in the near future. These include the role of mid-level providers; the future of the physician-scientist in our discipline; and potential modifications in training program structures to both attract more applicants, and to foster skills that better match the current and future needs of children with chronic respiratory disorders. These issues are all under discussion within the relevant regulatory and professional organizations, in the recent literature, ${ }^{24}$ and in the other two papers in this series produced by the PPDDA/PEPTDA working groups. ${ }^{18,25}$

In addition, there are other important stakeholders whose views are not represented in the current paper, but would clearly be required for a complete picture of workforce needs. These include the perspectives of patients and their families; referring primary care physicians; specialists in nonacademic medical centers; Department Chairs; leaders of public and private healthcare systems; and leaders of disease-specific foundations and advocacy groups supporting children with respiratory disorders.

The COVID-19 pandemic provides a striking example of how emerging pathogens can impact the nature of work and workforce needs for specialties like ours. While severe COVID-19 disease has fortunately not been a widespread problem in children thus far, the pediatric pulmonologist may possess valuable clinical skills applicable to adult patients ${ }^{26}$; and in future infectious outbreaks where children may be at higher risk, as they were in past influenza epidemics. ${ }^{27}$ From the research perspective, current $\mathrm{NIH}$ funding for infection and microbiome studies is robust (Table 7) and this suggests a future important area of focus for physician-scientists in our field. COVID-19 also quickly brought to the forefront the issues of safe use of ventilator systems and aerosols. As some of the "roots" of our specialty were in respiratory physiology, a return to cutting edge technical and physiologic knowledge in topics like ventilator circuits and strategies, particle and droplet physiology might represent an important niche moving forward. Ideally, this advancement in physiologic knowledge and technology would be in collaboration with biomedical engineering experts and with the medical device industry. In addition, the dramatic increase in the use of telehealth that was fueled by the pandemic may result in access to subspecialty care in regions where there are few or no practicing pediatric pulmonologists, although state licensure issues would need to be addressed. 
In light of national events as we write this in October 2020, we close with some comments on diversity within the field of pediatric pulmonology and its impact on our future. Despite a history of strong representation in clinical and research leadership roles for women in our field, like most academic medical disciplines we do not have a strong track record of inclusion of other groups who are historically underrepresented in medicine. Several of the conditions we treat, most notably severe asthma, respiratory complications of sickle cell disease, and now of course COVID-19, disproportionately affect underserved minority populations. Diversity is well understood to improve team performance in the business world, ${ }^{28}$ and faculty or provider diversity may improve clinical and educational outcomes. ${ }^{29,30}$ For our discipline to thrive in the future, to be effective educators, and to optimally serve children with chronic respiratory disorders, we need to work harder to minimize our explicit and implicit biases, and to nurture and sponsor colleagues who are members of underrepresented groups. This topic alone is worthy of a fourth workgroup from the Division Directors and Training Directors collective, that we hope will impact the future of pediatric pulmonology.

\section{ACKNOWLEDGMENTS}

The authors are grateful for the tremendous support of Eileen Larson and Rebecca Fisch (American Thoracic Society) in helping keep our workgroups productive despite the challenges of COVID-19. We also thank Adam Turner (American Board of Pediatrics) and Marrah Lachowicz-Scroggins (National Heart, Lung, and Blood Institute) for their helpful advice. We thank Dr. Erin Fraher (Director, Carolina Health Workforce Research Center at the Cecil G. Sheps Center for Health Services Research, UNC Chapel Hill) for providing perspective on the detailed pediatric subspecialty workforce assessments under way. Finally, the first two authors are extremely grateful to Melissa Brown, Keren Eyal, Benjamin Kaplan, Stephanie Jensen, Charles McLendon, Tam Ngyuen, Enioluwafe Ojo, Hunter Smith, Kelly Jo Tackett, Christopher Trennepohl, and Alana Zeitany, medical students and $\mathrm{MPH}$ candidates at The University of North Carolina at Chapel Hill, for their scrupulous work reviewing, coding, and analyzing the results of the NIH RePORT data download used in this study.

\section{ORCID}

Terry L. Noah (D) http://orcid.org/0000-0002-5134-3164

Charles R. Esther (D) https://orcid.org/0000-0002-8081-2986

Paul E. Moore (ID) http://orcid.org/0000-0001-5123-207X

\section{REFERENCES}

1. Harris C, Katkin J, Cataletto M, Dorkin H, Laskosz L, Ruch-Ross H. US pediatric pulmonology workforce. Pediatr Pulmonol. 2019;54:444-450.

2. Hayes D. Jr. Pediatric pulmonology workforce: an aging dilemma. Chest. 2014;146:e119-e120.

3. Redding GJ, Cloutier MM, Dorkin HL, Brotherton SE, Mulvey HJ. Practice of pediatric pulmonology: results of the Future of Pediatric Education Project (FOPE). Pediatr Pulmonol. 2000;30:190-197.

4. Weiss P, Mauer E, Gerber LM, Boyer D, Abramson EL. Funding sources and effects of limited funding in pediatric pulmonology fellowship programs. Pediatr Pulmonol. 2020;55:221-225.
5. Althouse LA, Stockman JA, 3rd. Pediatric workforce: a look at pediatric pulmonology data from the American Board of Pediatrics. J Pediatr. 2006;149:262-264.

6. Redding GJ. Is pediatric pulmonary research training in dire straits. Pediatr Pulmonol. 2010;45:34-35.

7. Ferkol T, Zeitlin P, Abman S, Blaisdell CJ, O'Brodovich H. NHLBI training workshop report: the vanishing pediatric pulmonary investigator and recommendations for recovery. Pediatr Pulmonol. 2010;45:25-33.

8. Zahran HS, Bailey CM, Damon SA, Garbe PL, Breysse PN. Vital signs: asthma in Children-United States, 2001-2016. MMWR Morb Mortal Wkly Rep. 2018;67:149-155.

9. Perry R, Braileanu G, Palmer T, Stevens P. The economic burden of pediatric asthma in the United States: literature review of current evidence. Pharmacoeconomics. 2019;37:155-167.

10. Agrawal A, Agarwal A, Mehta D, Sikachi RR, Du D, Wang J. Nationwide trends of hospitalizations for cystic fibrosis in the United States from 20013 to 2013. Intractable Rare Dis Res. 2017;6:191-198.

11. Wainwright CE, Elborn JS, TRAFFIC and TRANSPORT Study Groups, et al. Lumacaftor-ivacaftor in patients with cystic fibrosis homozygous for Phe508del CFTR. N Engl J Med. 2015;373:220-231.

12. Middleton PG, Mall MA, Dřevínek $P$, et al. VX17-445-102 study group. elexacaftor-tezacaftor-ivacaftor for cystic fibrosis with a single Phe508del allele. N Engl J Med. 2019;381:1809-1819.

13. Muller RG, Mamidala MP, Smith SH, Smith A, Sheyn A. Incidence, epidemiology, and outcomes of pediatric tracheostomy in the United States from 2000 to 2012. Oto-Head Neck Surg. 2019;160:332-338.

14. NIH RePORTER. The NIH Research Portfolio Online Reporting Tools (RePORT) [Internet]. Bethesda, MD: National Institutes of Health, Office of Extramural Research; 2019 [see Advanced Query screen]. https:// projectreporter.nih.gov/reporter.cfm. Accessed February 20, 2020.

15. Sawyer B, Claxton F. How do health expenditures vary across the population? [Internet]. Peterson KFF Health System Tracker; 2019. https:// www.healthsystemtracker.org/chart-collection/health-expenditures-varyacross-population/item-people-age-55-and-over-account-for-over-half-oftotal-health-spending_2016. Accessed October 15, 2020.

16. Bui AL, Dieleman JL, Hamavid H, et al. Spending on children's personal health care in the United States, 1996-2013. JAMA Pediatr. 2017; 171(2):181-189. https://doi.org/10.1001/jamapediatrics.2016.4086

17. NIH Data Book. NIH Budget History: NIH Budge Mechanism Detail, NIH Data Book Report ID: 226 [Internet]. Bethesda, MD: National Institutes of Health, Office of Intramural Research; 2019. https:// report.nih.gov/nihdatabook/category/1. Accessed October 15, 2020.

18. Esther, CR, Oermann CM, Ross K, Weiss P. Part III. Pediatric Pulmonology Fellowship Training. ATS Scholar; 2020. In press.

19. American Board of Pediatrics Data and Workforce. Interactive ABP Workforce Data [Internet]. Chapel Hill, NC: American Board of Pediatrics; 2020. https://www.abp.org/content/data-and-workforce. Accessed 15, October 2020.

20. Children's Hospital Association. [Internet]. Pediatric Workforce Shortages Persist. Lenexa, KS: Children's Hospital Association; 2020. https://www.childrenshospitals.org/Issues-and-Advocacy/ Graduate-Medical-Education/Fact-Sheets/2018/Pediatric-Workforc e-Shortages-Persist. Accessed October 15, 2020.

21. Collaco JM, Aherrera AD, Au Yeung KJ, Lefton-Greif MA, Hoch J, Skinner ML. Interdisciplinary pediatric aerodigestive care and reduction in health care costs and burden. JAMA Otolaryngol Head Neck Surg. 2015;141:101-105.

22. Storgion SA, Stutts AL. Transitional care: a multidisciplinary case management-based unit. Pediatr Nurs. 2000;26:564-568.

23. Abode KA, Drake AF, Zdanski CJ, Retsch-Bogart GZ, Gee AB, Noah TL. A multidisciplinary children's airway center: impact on the care of patients with tracheostomy. Pediatrics. 2016;137:e20150455.

24. Gaston B, Laguna TA, Noah TL, et al. A proposal for the addressing the needs of the pediatric pulmonary work force. Pediatr Pulmonol. 2020; 55:1859-1867. 
25. Boyer D, Lahiri T, Nelson B, Rama J Part II. Pediatric Pulmonology Trainee Pipeline. ATS Scholar; 2020. In press.

26. Kazachkov M, Murphy T, Noah TL. The roles of a pediatric pulmonologist during the COVID-19 pandemic. Pediatr Pulmonol. 2020;55: 2592-2595. https://doi.org/10.1002/ppul.25010

27. Glatman-Freedman A, Portelli I, Jacobs SK, et al. Attack rates assessment of the 2009 pandemic H1N1 influenza A in children and their contacts: a systematic review and meta-analysis. PLOS One. 2012;7(11):e50228.

28. Gompers P, Kovvali S. The other diversity dividend. Harvard Bus Rev. 2018;96:72-77.

29. Ingraham KC, Davidson SJ, Yonge O. Student-faculty relationships and its impact on academic outcomes. Nurse Educ Today. 2018;71:17-21.

30. Smedley BD, Stith AY, Nelson AR, eds. Unequal Treatment: Confronting Racial and Ethnic Disparities in Health Care. Committee on Understanding and Eliminating Racial and Ethnic Disparities in Health Care, Board on Health Sciences Policy, Institute of Medicine. Washington, DC: National Academies Press; 2002.

\section{SUPPORTING INFORMATION}

Additional supporting information may be found online in the Supporting Information section.

How to cite this article: Noah TL, Tolleson-Rinehart S, Esther CR, Peterson-Carmichael SL, Davis SD, Moore PE. The future of pediatric pulmonology: a survey of division directors, assessment of current research funding, and discussion of workforce trends.

Pediatric Pulmonology. 2020;1-9.

https://doi.org/10.1002/ppul.25228 